\title{
A UTILIZAÇÃO DA TECNOLOGIA NA LUTA CONTRA A VIOLÊNCIA DOMÉSTICA NO CONFINAMENTO DOMICILIAR
}

\author{
Fernanda Daltro Costa Knoblauch ${ }^{1}$
}

RESUMO: Este artigo enfrenta o problema do aumento dos índices de violência doméstica contra a mulher no período do confinamento domiciliar imposto pela disseminação da Covid19. Justifica-se a escolha desta temática em sua atualidade, relevância social e jurídica. Por conta da natureza qualitativa desta pesquisa, objetiva-se perquirir possíveis soluções tecnológicas para que as mulheres confinadas com seus agressores possam ter garantida sua segurança, ou, ao menos possam denunciar a violência sofrida, priorizando-se a análise teórica da problemática referida. Concluiu-se que as ferramentas tecnológicas se tornam estratégicas para o alcance da celeridade necessária às ações de inibição e contenção da violência.

PALAVRAS-CHAVE: violência doméstica. Violência de gênero. Covid-19. Pandemia. Tecnologia.

\section{THE USE OF TECHNOLOGY IN THE FIGHT AGAINST DOMESTIC VIOLENCE IN HOME CONTAINMENT}

\begin{abstract}
This article addresses the problem of the increase in domestic violence against women during the home confinement imposed by Covid-19. The choice of this theme is justified in its social and legal relevance. Due to the qualitative nature of this research, the objective is to investigate possible technological solutions so that women confined with their aggressors can have their safety guaranteed, or at least can denounce the violence suffered, prioritizing the theoretical analysis of the referred problem. It was concluded that the technological tools become strategic to achieve the necessary speed for actions to inhibit and contain violence.
\end{abstract}

KEYWORDS: domestic violence. Gender violence. Covid-19. Pandemic. Technology.

\section{INTRODUÇÃO}

\footnotetext{
1 Advogada. Doutoranda em Direito Civil pela Universidade de Coimbra. Mestre em Família na Sociedade Contemporânea pela Universidade Católica de Salvador. Pós-Graduada em Direito e Prática Previdenciária pela Faculdade Baiana de Direito. Pós-graduanda em Direito Médico pela Universidade de Coimbra. Pós-graduanda em Direito de Família pela Universidade de Coimbra. Bacharel em Direito pela Universidade Federal da Bahia. Salvador/BA, Brasil. fernandaknoblauch@gmail.com
} 
Este artigo tem por escopo apresentar um breve estudo acerca do enfrentamento ao problema da violência doméstica e familiar contra a mulher durante a pandemia causada pela disseminação do Covid-19 no Brasil.

O problema de pesquisa reside na verificação de que, face a situação de confinamento durante o estado de emergência instaurado por conta da disseminação global do vírus, noticia-se um factível aumento dos casos de violência doméstica contra a mulher. Justifica-se a escolha desta temática em sua atualidade e na lacuna presente no ordenamento jurídico, bem como afirma-se sua relevância social e jurídica face aos problemas que se descortinam durante o confinamento social.

Objetiva-se, desta forma, perquirir qual seria a solução adequada para que as mulheres que se encontram confinadas em seus domicílios juntamente com seus agressores possam ter garantida sua segurança durante a pandemia, ou, ao menos, que possam denunciar a violência sofrida. Ademais, há que se questionar, ainda, de que forma pode ser prestado o atendimento remoto a estes casos.

Para tanto, busca-se analisar a literatura nacional e internacional, por meio da realização de uma breve revisão doutrinária sobre conceitos essenciais à pesquisa, para que se possa relacioná-los conforme o enfoque adotado neste artigo.

Por conta da natureza qualitativa atribuída à esta pesquisa, busca-se descrever e interpretar os índices de violência contra a mulher no Brasil nos últimos anos, bem como verificar, com base nas notícias já divulgadas, uma tendência de aumento do mesmos, indagando-se de que forma se pode garantir a segurança das vítimas durante este período. No que se refere às técnicas e procedimentos metodológicos utilizados, realizou-se uma pesquisa teórica, priorizando uma análise teórica acerca da problemática referida.

A abordagem também foi feita por meio de pesquisa documental, com análise de conteúdo, utilizando-se de procedimento de pesquisa com base na tipologia jurídicoprospectiva, com recurso tanto a dados primários quanto a dados secundários, oriundos de fontes jurídicas tradicionais. 


\section{O SIMbOLISMO PENAL NA LEI MARIA DA PENHA - DADOS ESTATÍSTICOS E PROJEÇÕES}

A violência doméstica e familiar contra a mulher é uma temática peculiar, tendo em vista, sobretudo, que este fenômeno é de natureza estrutural (BIANCHINI, 2017, p. 190/191), originando-se nas desigualdades históricas e valorativas aos papeis atribuídos ao homem e à mulher dentro da relação conjugal e familiar (BOURDIEU, 2012 e ENGELS, 2016). Verifica-se que, rotineiramente, a violência doméstica é praticada no âmbito das relações de dominação pré-estabelecidas, tendo por vítimas preferenciais mulheres, crianças, adolescentes e idosos, em razão de sua fragilidade ou vulnerabilidade dentro do núcleo familiar.

Acerca das leis e do próprio processo legislativo em Direito Penal, fica evidenciado que "uma verificação da história mostra que o direito penal serviu (e continua servindo) de instrumento de dominação" (XAVIER; TEIXEIRA, 2017. p. 362). Com base nesta afirmação é que se busca lançar um olhar crítico para as legislações que se propõem a combater a prática da violência doméstica, tendo em vista, sobretudo, o fato de que as mesmas se inserem na perspectiva da expansão do Direito Penal.

Um claro exemplo de legislação simbólica no âmbito da violência doméstica e familiar é a Lei nº 11.340/06 (Lei Maria da Penha), no ordenamento jurídico brasileiro. A sua criação se deu em virtude de uma condenação sofrida pelo Brasil no âmbito da Comissão Interamericana de Direitos Humanos da OEA (no processo de $n^{\circ} 12.051 / \mathrm{OEA}$ ) em virtude do reconhecimento de que houve negligência, omissão e tolerância na apreciação judicial do caso de Maria da Penha Maia Fernandes, que foi vítima de violência doméstica por mais de 23 anos, na constância de seu casamento com o agressor Marco Antônio Heredia Viveros.

A comissão da OEA, ao afirmar que no Brasil inexistiam mecanismos eficientes para coibir a prática de violência doméstica contra a mulher, condenou o Brasil a reparar materialmente e simbolicamente a vítima pela morosidade na condução do processo penal, bem como a finalizar o processo penal contra o agressor. Mais ainda, foi estipulado pela OEA que o Estado brasileiro adotasse políticas públicas destinadas a prevenir, punir e erradicar a 
violência contra a mulher, o que culminou na edição da Lei $n^{\circ} 11.340 / 06$, denominada de Lei Maria da Penha, em alusão à vítima que se tornou símbolo internacional.

A afirmação de que a Lei Maria da Penha é fruto de um processo legislativo emergencial, feito de forma rápida e casuística, atendendo a interesses e pressões populares e midiáticos, sendo, portanto, uma evidente legislação simbólica, não possui o intuito de retirar sua importância histórica ou mesmo sua relevância dentro do ordenamento jurídico brasileiro. Busca-se apenas, e mais uma vez, evidenciar o fato de que o poder legislativo assumiu uma competência que teria sido destinada ao executivo, já que a condenação fazia clara alusão a políticas públicas, e não a mais um instrumento de criminalização e agravamento de punição às condutas já tipificadas.

Para que se possa atestar o simbolismo da Lei Maria da Penha no ordenamento brasileiro e o fato de que, a mera tipificação legal ou agravamento das penas referentes às condutas de violência doméstica não é mecanismo suficiente para coibir estas práticas, enxerga-se a relevância de se apresentar os índices da violência contra as mulheres no Brasil, que constam nas pesquisas denominadas Mapa da Violência: Homicídios de Mulheres no Brasil, de 2015, (WAISELFISZ, 2015) e Atlas da Violência, de 2019 (CERQUEIRA, BUENO, 2019).

$\mathrm{Da}$ análise conjunta dos documentos, pode-se extrair que, tem havido um aumento sistemático nos índices de violência doméstica, onde as vítimas preferenciais são as mulheres, e os principais agressores são aqueles com quem elas possuem um relacionamento mais próximo.

Note-se que estes estudos se referem a períodos nos quais não havia nenhum impedimento de ordem fática para que se pudesse recorrer aos institutos previstos no corpo da legislação, tais como o afastamento compulsório entre vítima e agressor, inclusive com a possibilidade de remoção de seus domicílios, conforme Art. 12C da Lei no 11.340/06. Atualmente, ante ao estado de emergência que acompanha a progressão da pandemia, tal medida mostra-se de difícil realização, considerada a quarentena e o isolamento social que deve ser mantido durante este período.

Desta forma, pode-se afirmar que a principal forma até agora encontrada de combate da contaminação pelo Sars-Cov-2 ("Severe acute respiratory syndrome coronavirus 2", ou, simplesmente, novo Coronavírus), em denominação adotada pela Organização Mundial de 
Saúde (OMS), qual seja o isolamento social no domicílio é também um fator de risco para as vítimas potenciais da violência doméstica, pelo aumento do tempo de convívio com os potenciais agressores.

No Mapa da Violência, que limita sua análise aos homicídios de mulheres no Brasil, verifica-se que "entre 2003 e 2013, o número de vítimas do sexo feminino passou de 3.937 para 4.762, incremento de 21,0\% na década. Essas 4.762 mortes em 2013 representam 13 homicídios femininos diários." (WAISELFISZ, 2015). Mais ainda, alarmante o fato de que "Limitando a análise ao período de vigência da Lei Maria da Penha, que entra em vigor em 2006, observamos que a maior parte desse aumento decenal aconteceu sob égide da nova lei: 18,4\% nos números e 12,5\% nas taxas, entre 2006 e 2013.” (WAISELFISZ, 2015).

Em atualização promovida em 2019 pelo Atlas da Violência, verificou-se que até 2017 (período em que foi realizada a coleta de dados), houve um crescimento ainda maior do número do homicídio de mulheres, totalizando 4.936 mortes neste ano, o maior número já registrado desde 2007. (CERQUEIRA, BUENO, 2019). Ressalte-se que a Lei Maria da Penha entrou em vigor em 21 de setembro de 2006, desta forma, prova-se que a mera inclusão desta lei no ordenamento brasileiro não foi capaz de frear o aumento do número de homicídios de mulheres no Brasil.

Para o ano de 2020, pesquisadores apontam que a quarentena será um fator a elevar ainda mais os índices de violência doméstica. Muito embora aduza que o tempo de análise ainda é muito curto para que se possam constituir dados oficiais, a socióloga Wania Pazzinato assevera que existe uma tendência já verificada de que "momentos de crise na sociedade econômica, política ou uma pandemia - historicamente trazem aumento da violência contra a mulher. Foi assim com o ebola na África e a cólera no Haiti." Em mesmo sentido, aponta Valéria Scarance, membro do Núcleo de Gênero do MPE-SP: “É um padrão aprendido ao longo da vida por parte dos homens. Algumas situações de estresse funcionam como gatilho para esse comportamento". (conforme reportagem ISTOÉ edição no 2622 10/04. Reportagem 03/04/2020: Quarentena eleva risco de violência doméstica.)

Embora não seja possível atribuir todos os homicídios femininos como sendo decorrentes da violência doméstica, por meio da análise do local onde eles ocorreram, pode-se ter uma melhor noção acerca destes índices. De fato, enquanto nos homicídios masculinos o 
lar não aparece como um local de destaque, no que se refere aos homicídios femininos, ele ocupa o segundo lugar na pesquisa, só perdendo para a rua.

Quase a metade dos homicídios masculinos acontece na rua, com pouco peso do domicílio. Já nos femininos, essa proporção é bem menor: mesmo considerando que $31,2 \%$ acontecem na rua, o domicílio da vítima é, também, um local relevante $(27,1 \%)$, indicando a alta domesticidade dos homicídios de mulheres. (CERQUEIRA, BUENO, 2019, p. 39).

O Atlas da Violência de 2019, apresenta uma tendência ainda mais preocupante, já que prova que houve um aumento dos homicídios femininos no lar e uma redução destes na rua, o que prova que mesmo o Brasil estando em uma tendência de diminuição gradativa da violência geral, os índices de violência doméstica, pelo contrário, só aumentam.

Um pequeno aumento na taxa de homicídio de mulheres (1,7\%), entre 2012 e 2017. Porém, quando desagregamos esse indicador entre os homicídios que ocorreram fora e dentro da residência, verificamos dois comportamentos distintos. Ao mesmo tempo em que a taxa de homicídios fora da residência diminuiu 3,3\% no período, o segundo indicador aumentou $17,1 \%$. Possivelmente, a redução de homicídios de mulheres fora da residência esteja refletindo a diminuição gradativa da violência geral que tem se expandido cada vez mais para um maior número de unidades federativas. Por outro lado, o crescimento dos casos que ocorrem dentro das residências deve ser reflexo do aumento de casos de feminicídios, efetivamente. (CERQUEIRA, BUENO, 2019, p. 40).

Ao se referir à violência não-letal, os índices tornam-se ainda mais preocupantes. No Brasil, em 2014,

Foram atendidas 223.796 vítimas de diversos tipos de violência. Duas em cada três dessas vítimas de violência (147.691) foram mulheres que precisaram de atenção médica por violências domésticas, sexuais e/ou outras. Isto é: a cada dia de 2014, 405 mulheres demandaram atendimento em uma unidade de saúde, por alguma violência sofrida. (CERQUEIRA, BUENO, 2019, p. 42).

Destas agressões, foi constatado que $71,9 \%$ foram sofridas pelas mulheres em suas residências.

A residência é o local privilegiado de ocorrência da violência não letal, para ambos sexos; significativamente superior para o sexo feminino $(71,9 \%)$, em relação ao masculino $(50,4 \%)$. Em segundo lugar, a rua, local de ocorrência de $15,9 \%$ das violências atendidas, no caso feminino, contra $30,6 \%$ dos atendimentos masculinos. (CERQUEIRA, BUENO, 2019, p. 50). 
Para que não restem dúvidas de que tais casos se enquadram como sendo de violência doméstica, as pesquisas apontam ainda que 67,2\% dos casos registrados podem ser atribuídos a parentes imediatos, parceiros e ex-parceiros.

$82 \%$ das agressões a crianças do sexo feminino, de $<1$ a 11 anos de idade, que demandaram atendimento pelo SUS, partiram dos pais - principalmente da mãe, que concentra 42,4\% das agressões. Para as adolescentes, de 12 a 17 anos de idade, o peso das agressões divide-se entre os pais $(26,5 \%)$ e os parceiros ou ex-parceiros $(23,2 \%)$. Para as jovens e as adultas, de 18 a 59 anos de idade, o agressor principal é o parceiro ou ex-parceiro, concentrando a metade do todos os casos registrados. Já para as idosas, o principal agressor foi um filho $(34,9 \%)$. No conjunto de todas as faixas, vemos que prepondera largamente a violência doméstica." (CERQUEIRA, BUENO, 2019, p. 48).

Resta fora de questão a lacuna de eficácia da Lei Maria da Penha como ferramenta preventiva e punitiva da violência doméstica pois, a pesquisa em questão, assevera que "a reincidência acontece em praticamente metade dos casos de atendimento feminino $(49,2 \%)$, especialmente com as mulheres adultas $(54,1 \%)$ e as idosas $(60,4 \%)$ ". (CERQUEIRA, BUENO, 2019, p. 51).

Tratando-se de 2020, pode-se apontar desde já diversos problemas que poderão vir a mascarar o aumento real destes números: o primeiro deles é o fato de que o atendimento médico encontra-se preferencialmente voltado às vítimas do Covid-19, desta forma, está sendo aconselhado que as pessoas evitem ir aos hospitais e emergências pelo risco de contágio, devendo permanecer em seu ambiente doméstico quando possível. Um outro problema é a dificuldade imposta às vítimas de conseguir denunciar seu agressor, já que qualquer enfrentamento pode ocasionar uma nova situação de violência. No mais, a manutenção da convivência, por si só, já se afigura problema suficiente para ser levado em consideração. (Conforme aponta o PORTAL R7 em reportagem de Nayara Fernandes publicada em 01/04/2020. Título: "Sem lugar seguro: quarentena expõe crise de violência doméstica no País.").

Nota-se que, mesmo que se verifique o crescimento dos índices, sabe-se desde já que a maior parte dos casos poderá acabar indo integrar o que se convencionou chamar de cifras ocultas, não se podendo precisar, ao certo, o índice de reincidência ou de novos casos de violência doméstica, já que, para as agressões leves, as marcas físicas passarão antes que seja possível a realização dos exames físicos. Nos casos em que a violência é psicológica, 
patrimonial ou moral, mais difícil ainda de se alcançar uma estatística que corresponda à realidade.

Dito isto, já nesta fase inicial do confinamento doméstico, nota-se a repetição de um padrão já verificado em outros países, também no território brasileiro:

Outros países também registraram aumento das agressões dentro de casa desde o início da pandemia. A França anunciou esta semana que pagará quartos de hotel para vítimas de violência doméstica e abrirá centros de aconselhamento após o aumento dos casos de abuso na primeira semana de quarentena. O acréscimo foi de $36 \%$ em Paris e $32 \%$ no resto do país após o confinamento, no dia 17. Houve ainda dois assassinatos. (conforme reportagem ISTOÉ edição $n^{\circ} 2622$ 10/04. Reportagem 03/04/2020: Quarentena eleva risco de violência doméstica.)

O aumento das denúncias de violência doméstica, sejam estas realizadas nos canais oficiais do governo quanto nos canais não-oficiais, tais como institutos e ONG's que trabalham com a proteção e o acolhimento das vítimas. (A título de exemplo: G1SC e NCSTV - 06/04/2020; G1 Itapetininga e Região - 05/04/2020; Portal R7 Nayara Fernandes de 01/04/2020; e ISTOÉ. Edição no 2622 10/04.)

Ante o exposto, pode-se afirmar que, muito embora a Lei Maria da Penha possa ser vista como um avanço no combate à violência doméstica e familiar contra as mulheres, a mesma tem sido pouco eficaz (ou mesmo inócua) no real combate diário da violência. Este é um dos principais problemas do recurso às legislações simbólicas: muito embora possa parecer que o Estado está se empenhando em resolver o problema da criminalidade por meio da imposição de uma lei severa, a aplicação deste instrumento normativo mostra-se falha e ineficaz, o que, a longo prazo, vai servir como outro elemento apto a realçar a sensação de insegurança na população.

Mais ainda, a Lei Maria da Penha não possui nenhum dispositivo que seja eficaz na prevenção e no combate da violência doméstica durante a quarentena, sobretudo por conta da impossibilidade de recurso aos seus principais artigos, que cuidam das medidas liminares para fazer cessar a violência. Desta forma, entende-se que o executivo deve (re)assumir a função que lhe é cabível, por meio da elaboração de medidas e políticas públicas que possam prestar auxílio às mulheres (e outras pessoas que se encontrem em situação de vulnerabilidade domiciliar) durante este período. 


\section{FERRAMENTAS TECNOLOGICAS - ARSENAL PODEROSO NA LUTA CONTRA A VIOLÊNCIA DOMÉSTICA}

Ante ao panorama exposto, e antecipando a tendência de aumento dos casos de violência doméstica e familiar contra a mulher já verificados em outros países nos quais o isolamento social e a quarentena domiciliar se iniciaram antes do que no Brasil, a exemplo da China, França, e Portugal, questiona-se de que modo o Brasil pode tentar conter a progressão numérica dos casos de violência doméstica, já em curso, conforme referido, durante a pandemia.

Há que se pontuar que o confinamento e a convivência forçada são, de fato, gatilhos que atuam diretamente na acentuação de questões emocionais pré-existentes, o que se soma à tensão psicológica da época em que se vive, de medo, incerteza e insegurança. (de acordo com site MEDIUM. Escritora Gabriela Moura. Violência contra a mulher aumenta com pandemia de Covid-19 - Quarentena deixa mulheres mais vulneráveis a seus agressores.). Neste período, transtornos mentais e comportamentais podem aflorar ou mesmo se expandirem, dificultando mais ainda a convivência domiciliar. Pode-se, a título de exemplo, listar alguns transtornos possíveis de ocorrer em situações que importem em restrições, confinamento e clausura; são eles: ansiedade, depressão, esquizofrenia, transtornos alimentares, estresse, somatização, bipolaridade, comportamento violento ou obsessivo compulsivo, dentre tantos outros. Obviamente, não se busca justificar a prática da violência em questões médicas e psicológicas, aponta-se apenas que tanto agressor quanto vítima, no período do confinamento, podem estar passando por um destes transtornos, o que complica ainda mais as relações familiares.

Como se atravessa uma crise onde se faz essencial haver a manutenção de restrições ao ir e vir das pessoas, logicamente, as relações de convivência, em um mesmo espaço físico ficam ainda mais tensionadas pelo isolamento social imposto. Não se pode ignorar que lares onde já existiam casos de violência doméstica e familiar são uma realidade a nível mundial, realidade essa que tende a se avultar em momentos críticos como o do recolhimento domiciliar imposto visando contingenciar a propagação da Covid-19. Mais ainda, mesmo em lares que não tinham histórico de violência, o convívio forçado e as adversidades impostas pela clausura podem levar à emergência de novos casos de violência doméstica. 
Malgrado a realidade fática atual, a luta contra a violência de gênero e contra a violência doméstica familiar não pode esmorecer ou ser relegada a segundo plano e, mais do que nunca, pugna e requer monitoramento estatal preventivo e repressivo, atrelado a providencias imediatas enérgicas, que possibilitem a proteção de toda e qualquer pessoa que se sinta ameaçada ou já tenha sido vitimada.

Dentre as vantagens do mundo hiper conectado, destaca-se o grande leque de ferramentas de comunicação a nível virtual/digital, bem como a acessibilidade aos dispositivos básicos de comunicação, a exemplo do celular e da conexão à internet. Em uma situação de calamidade pública, na qual recomenda-se à população o isolamento domiciliar, as ferramentas tecnológicas figuram como aliadas estratégicas para maior uso estatal, visando impor um alcance e celeridade ampla a todo tipo de ações.

Vivemos em uma época na qual as pessoas não se conectam à Internet apenas para atividades específicas, mas que permanecem continuamente online nas ruas, em suas casas, no trabalho e na escola. Isso gera uma inovação acelerada e grandes oportunidades em termos de negócios, com empresas descobrindo novos públicos, criando novos fluxos de receita e diferentes modelos de atuação. (TIINSIDE, Alex Felipelli, 09/09/13)

O fato de a tecnologia se encontrar atrelada a vida da maioria quase absoluta das pessoas faz-se cabal no aproveitamento dela como ferramenta propiciadora de maior comodidade. Empresas e microempresas privadas, bem como uma ampla gama de profissionais estão se adaptando à situação que se vive, buscando fornecer produtos, serviços e conteúdo online ou por entrega em domicílio, para manter sua fonte de lucro e renda. $\mathrm{O}$ próprio Estado já se utiliza da tecnologia para a transmissão de seus pronunciamentos e medidas emergenciais e de contenção.

Comunicados a nível nacional são transmitidos pelas televisões, ou mesmo pulverizados em mensagens de texto, os sites fazem uma cobertura em tempo real da progressão da doença e das soluções até então encontradas, aplicativos são criados para atender às mais diversas funções, desde transmissão de informações básicas a cadastros em programas governamentais de redistribuição de renda aos mais necessitados, doações podem ser realizadas em poucos cliques, bem como a aquisição de alimentos e produtos essenciais, que são entregues à porta de casa. 
Mas, como fica a prestação da atividade policial em tempos de isolamento social? Como a polícia pode atuar, com o recurso à tecnologia, para prevenir e reprimir os crimes de violência doméstica remotamente?

Decerto, o avanço técnico e tecnológico proporcionou a criação de um sistema policial que incorporou as inovações tecnológicas, no intuito de melhorar o atendimento ao cidadão. A tecnologia se enraizou plenamente, integrando-se, também, na seara de âmbito policial criminal. Meios foram disponibilizados através da criação de várias Delegacias Digitais, detentoras de acesso digital para registro remoto de ocorrências pelas vítimas. Notese, que, entretanto, há uma gama restrita de denúncias que podem ser feitas pela plataforma digital, e que, na maioria dos casos, a vítima ainda necessita deslocar-se até uma delegacia ou posto de atendimento.

Entretanto, o que se verifica é que, devido ao isolamento forçoso, as pessoas que já vivenciavam situações de vulnerabilidade física, moral e psicológica dentro dos seus lares ficaram ainda mais expostas à violência. $\mathrm{O}$ afastamento compulsório das vítimas de suas principais redes de apoio, tais como familiares, amigos, psicólogos e outros profissionais da saúde agrava ainda mais a situação. Ante o aumento do convívio doméstico com os potenciais agressores, e o distanciamento social daquelas pessoas e entidades que lhe prestam apoio, verifica-se que cabe ao Estado intervir, de forma mais incisiva, numa tentativa de suprir as dificuldades agravadas neste período.

Desta forma, afirma-se que os serviços policiais remotos especializados necessitam se fazer mais acessíveis ao cidadão, sendo a ferramenta de registro de ocorrências digital a melhor plataforma a ser utilizada para minorar as dificuldades envolvendo denúncias de violências no âmbito doméstico familiar. Ao se possibilitar a denuncia dos crimes de violência doméstica e familiar virtualmente, permite-se que as vítimas tenham um meio de registrar, de forma oficial, qualquer tipo de violência sofrida, que será apurada em momento posterior, ou, conforme a gravidade da situação, pode dar ensejo à aplicação de uma medida protetiva imediata.

Ressalte-se, ainda, que a atividade policial deve ser realizada de forma conjunta e coordenada com o Ministério Público, Defensoria Pública e Poder Judiciário, da forma como prevista em Lei. A utilização dos meios virtuais vem apenas para facilitar o acesso do cidadão e evitar que o mesmo se coloque em risco de contrair o vírus em uma incursão a uma 
delegacia ou posto de atendimento, mas que também, não deixe de reportar a violência sofrida durante este período.

No Brasil, alguns estados já tomaram a iniciativa de flexibilizar a denúncia dos crimes de violência doméstica e familiar pela internet, a exemplo de São Paulo e Minas Gerais, cujos exemplos precisam ser enaltecidos e seguidos, visando um maior alcance, de forma urgente, em todo o país, inclusive com o alinhamento e uniformização das práticas e das ferramentas tecnológicas.

O estado de São Paulo, além de disponibilizar o registro virtual de ocorrências envolvendo violência doméstica, estuda meios para o alcance do aceite virtual de fotos comprobatórias da violência registrada. (São Paulo. do Portal do Governo 03/04/2020; GRUPO LIBERAL. da redação 03/04/2020; Link para a Delegacia Eletrônica de São Paulo: https://www.delegaciaeletronica.policiacivil.sp.gov.br/).

Por óbvio, tais informações e imagens serão analisadas pelos profissionais competentes, para verificar a ocorrência ou não do crime e da lesão, de forma similar à que seria realizada no curso normal do inquérito/processo.

Outro exemplo, mais recente, de uso eficaz da tecnologia, vem de Minas Gerais, onde a Polícia Civil informa haver antecipado o lançamento de uma ferramenta de utilização de videoconferência ali denominada de "Plantão Digital", no sentido de proporcionar economia de tempo e dinheiro, bem como possibilitar a manutenção das prestações dos serviços policiais e investigativos essenciais. A referida ferramenta servirá, também, para permitir a manutenção do afastamento social, um item precioso da luta para evitar um contágio maior através da Covid-19 uma vez que, os profissionais e os cidadãos se comunicam por meio de uma sala virtual.

De acordo com informações repassadas pela polícia local, (G1 Minas - 07/04/2020), o Plantão Digital trata-se de uma ferramenta de vídeo conferência que já estava sendo desenvolvida e testada desde o mês de janeiro deste ano e seria lançada, oficialmente, apenas no mês de agosto de 2020, ferramenta esta que, devido a pandemia virótica, teve sua implantação antecipada.

Importa acentuar e destacar a relevância das investigações tecnológicas criminais, a exemplo de outros procedimentos de investigação, necessitarem continuadamente de se 
atentar e pautar, no que diz respeito a se desenvolverem em total conformidade com os regramentos e os princípios contidos na Constituição Federal de 1988. As ações da polícia investigativa devem sempre tomar por base o rigor técnico, legal, no sentido de embasar as provas produzidas ou obtidas através de um ambiente tecnológico e, assim, poder cumprir todo o alcance da lei.

Na Bahia, a Comissão da Mulher da OAB/BA, já se manifestou no sentido de reconhecer a necessidade do recurso à tecnologia no combate à violência doméstica e familiar contra a mulher, afirmando, inclusive, o valor da iniciativa tomada no estado de São Paulo. (conforme Instagram - Comissão de Proteção aos Direitos da Mulher da OAB-Ba). É de se esperar que, nos próximos dias, mais estados adiram à esta iniciativa, de forma a prestar uma atenção especializada a estes casos, considerando-se o fato de que o perigo é imediato e necessita de urgente intervenção estatal.

Ademais, não se pode olvidar de mencionar a relevância da criação, também, de redes de apoio virtuais pelas ONG's, como o exemplo do projeto Justiceiras, (whatsapp (11) 99639-1212 ou pelo Instagram, no perfil @Justicadesaia), que é uma iniciativa com 500 voluntárias na área do Direito, Psicologia e Assistência Social que visa acolher e aconselhar virtualmente mulheres vítimas de violência doméstica na quarentena.

Um exemplo de rede de apoio que vem se expandido na Europa é a utilização, pelas vítimas, de uma palavra-chave (Mascarilla-19, que pode ser traduzida como Máscara-19) em suas idas às farmácia e mercados; por meio da utilização desta expressão, o farmacêutico ou atendente faria um pedido de ajuda por meio do contacto às autoridades competentes. A campanha inspira-se em histórias que aconteceram em Nancy, na França, e nas Ilhas Canárias, na Espanha, contando também com o apoio estatal. (EXPRESSO. por Marta Gonçalves 08/04/2020.).

Ante os dados coletados e analisados no Brasil, pode-se afirmar que a violência doméstica e familiar contra a mulher é sistêmica e repetitiva, e que as elevadas taxas de reincidência neste delito deveriam levar os Estados a repensar as ferramentas de prevenção e combate deste tipo delitual, tendo em vista, sobretudo, a falência do sistema criminal como substitutivo das políticas públicas que podem reduzir a desigualdade de gênero e a gênese da criminalidade. Combater o avanço da criminalidade por meio do recurso à tecnologia, neste momento, é essencial, e deve ser feito de forma emergencial. 
Passada a crise, cogita-se também a manutenção, no ordenamento, desta possibilidade de denúncia, caso verificada a sua pertinência e o seu valor no combate a estes crimes. A tecnologia é uma ferramenta útil, e a sua correta utilização pode ser uma aliada no combate ao crime e à reincidência.

\section{CONCLUSÃO}

Embora a Lei Maria da Penha represente um grande e importante avanço no combate à violência doméstica e familiar contra as mulheres no Brasil, a referida lei não se fazia apta e bem preparada para arcar com o enfrentamento fático da violência doméstica durante a quarentena, trazida a reboque pela atual pandemia de saúde pública. O imprescindível confinamento residencial e social, fator importantíssimo para o combate a disseminação do vírus, se traduziu em perigosa faca de dois gumes para as pessoas já vitimadas pela violência doméstica, posto que a convivência diária contínua e forçada acirra ânimos, faz o estresse aumentar, principalmente em ambientes que já repercutem violência.

A crise pandêmica ressalta lacunas jurídico/legais de ações que precisam ser, urgentemente, sanadas ou, pelo menos, minoradas e mitigadas. O interesse maior reside na prestação eficiente de auxílio às mulheres (e outras pessoas que se encontrem em situação de exposição e vulnerabilidade domiciliar). Necessário, mais do que nunca, conter no Brasil a tendência de aumento do número de casos de violência doméstica familiar contra a mulher, já verificada em outros países acometidos pela Covid-19. Para o alcance disto, deve-se lançar mão do grande leque de ferramentas tecnológicas do qual dispomos na atualidade. Estas ferramentas se tornam estratégicas para o alcance da celeridade necessária as ações de inibição e contenção da violência.

As tecnologias que dispomos se exponencializam em momentos de restrições de locomoção como o atual. Momentos em que ações rápidas se fazem necessárias no combate à prática dos mais diversos crimes. Casos que envolvem violência doméstica não podem ser mascarados, principalmente em épocas de crise. Graves e profundos problemas sociais como esses, necessitam ser combatidos todos os meios de enfrentamento possíveis. Adiar-se o 
enfrentamento real destas questões é ainda mais grave, posto que a reincidência delitiva é um dos principais elementos que acaba por levar ao feminicídio.

Desta forma, e mesmo diante da constatação de que os estudos ainda se encontram em estágio preliminar, cabendo maiores análises, já se pode asseverar a imperiosa necessidade de aumento e incremento do arsenal tecnológico no sentido de evitar-se vitimar mais mulheres a cada dia de confinamento. Ao combate e a contenção da onda de violência deve-se atrelar, também, a busca de mudanças operacionais mais favoráveis a real aplicação e efetivação da lei pátria.

Fato cabal é que uma pandemia, como a causada pelo Sars-Cov-2, expõe fragilidades e provoca situações adversas de grande porte. Cobra ações mais imediatas e abrangentes do poder público. Crises agudas descortinam problemas, que precisam ser enfrentados e solucionados de imediato, por meio de iniciativas rápidas, pontuais e efetivas. São situações a exigir ampla percepção voltada para o amparo e ajuda aos semelhantes que requerem e pugnam pela busca da justiça; que abrem os olhos dos governantes e, de toda a sociedade, para problemas estruturais mal resolvidos ou não solucionados. Mais uma vez, afirma-se que é preciso sanar as causas do problema e não simplesmente empregar-se remédios paliativos, que apenas protraem no tempo o enfrentamento do problema estrutural que se apresenta.

A pandemia da atualidade deteve o condão de precipitar a utilização e emprego de um arsenal tecnológico poderoso e eficaz. Arsenal este que vinha tendo o seu avanço contido, adiado, até menosprezado e subutilizado pela grande maioria dos órgãos voltados às demandas públicas.

Observe-se, também, através do caótico ano de 2020, um fato sempre assente em todas as grandes e graves crises já perpassadas historicamente pela humanidade, o do panorama desafiador da crise ensejar e propiciar melhores e mais centradas condições para o alcance de visualizações de abertura para modificações de talantes funcional, estrutural e econômico; casos como o reportado através da chaga aberta configurada através da violência ocorrida no âmbito doméstico/familiar.

Finaliza-se deixando espaço para novas reflexões e interpretações, em virtude do que se indica a necessidade de realização de pesquisas, mais amplas e detalhadas, referentes ao assunto. Tem-se esperança de que o recurso à tecnologia no combate aos casos de violência doméstica e familiar se mostre uma ferramenta útil e adequada, e que sua utilização possa ser 
expandida mesmo após a passagem do epicentro da crise. Que estas iniciativas de modernização do sistema de denúncias possam ser implantadas em todo o país, de forma que se possa mapear mais eficazmente a violência, para que, então, adeque-se a utilização da Lei Maria da Penha, para que a mesma ganhe maior efetividade.

\section{REFERÊNCIAS}

BIANCHINI, Alice. Aplicação da justiça restaurativa para crimes que envolvem violência de gênero contra a mulher? 173-194 pp In: VALOIS, Luiz Carlos; SANTANA, Selma; MATOS, Taysa; ESPIÑEIRA, Bruno. [Orgs.] JUSTIÇA RESTAURATIVA. Belo Horizonte: D’Plácido, 2017, 497 p.

BOURDIEU, Pierre. A Dominação Masculina. 11 ed. Rio de Janeiro: Bertrand Brasil, 2012, $172 \mathrm{p}$.

BRASIL. LEI No 11.340, de 7 de agosto de 2006. Cria mecanismos para coibir a violência doméstica e familiar contra a mulher, nos termos do $\S 8$ o do art. 226 da Constituição Federal, da Convenção sobre a Eliminação de Todas as Formas de Discriminação contra as Mulheres e da Convenção Interamericana para Prevenir, Punir e Erradicar a Violência contra a Mulher; dispõe sobre a criação dos Juizados de Violência Doméstica e Familiar contra a Mulher; altera o Código de Processo Penal, o Código Penal e a Lei de Execução Penal; e dá outras providências. Diário Oficial. Disponível em: <http://www.planalto.gov.br/ccivil_03/_ato 2004-2006/2006/lei/ 111340.htm>. Acesso em: 10 abr. 2020.

LEI No 13.827, de 13 de maio de 2019. Altera a Lei no 11.340, de 7 de agosto de 2006 (Lei Maria da Penha), para autorizar, nas hipóteses que especifica, a aplicação de medida protetiva de urgência, pela autoridade judicial ou policial, à mulher em situação de violência doméstica e familiar, ou a seus dependentes, e para determinar o registro da medida protetiva de urgência em banco de dados mantido pelo Conselho Nacional de Justiça. Diário Oficial. Disponível em: <http://www.planalto.gov.br/ccivil_03/_Ato2019-2022/2019/Lei/ L13827.htm\#art2>. Acesso em: 10 abr. 2020.

BUENO, Mariana Guimarães Rocha da Cunha. Feminismo e Direito Penal. 2011. 180 f. Dissertação (Direito Penal). Faculdade de Direito, Universidade de São Paulo. São Paulo, 2011. Disponível em: <http://www.teses.usp.br/teses/disponiveis /2/2136/tde-140520121614 11/pt-br.php> Acesso em: 15 ago. 2019.

CERQUEIRA, Daniel. BUENO, Samira. (coord). ATLAS DA VIOLÊNCIA 2019. Ipea e FBSP. Disponível em: <http://www.ipea.gov.br/portal/images/stories/PDFs/relatorio_institu cional/190605_atlas_da_violencia_2019.pdf>. Acesso em: 02 abr. 2020.

ENGELS, Friedrich. Tradução: KONDER, Leandro. A Origem da Família, da Propriedade Privada e do Estado. 2. ed. Rio de Janeiro, BestBolso. 2016, 223 p.

EXPRESSO. por Marta Gonçalves - 08/04/2020. "Máscara-19": uma campanha para ajudar vítimas de violência doméstica que não está (nem esteve) a funcionar. Disponível em: <https://expresso.pt/coronavirus/2020-04-08-Mascara-19-uma-campa nha-para-ajudar- 
vitimas-de-violencia-domestica-que-nao-esta--nem-esteve--a-funcionar -1>. Acesso em: 12 abr. 2020.

G1.COM. por G1 Itapetininga e Região - 05/04/2020. Número de denúncias por violência doméstica aumenta durante a quarentena em Itapetininga. Disponível em: <https://g1. globo.com/sp/itapetininga-regiao/noticia/2020/04/05/numero-de-denuncias-por-violenciadomestica-aumenta-durante-a-quarentena-em-itapetininga.ghtml>. Acesso em: 12 abr. 2020.

por G1 Minas - 07/04/2020. Coronavírus: Polícia Civil antecipa lançamento do

“Plantão Digital”. Disponível em: <https://g1.globo.com/mg/minas-gerais/noticia /2020/04/ 07/coronavirus-policia-civil-antecipa-lancamento-do-plantao-digital.ghtml > . Acesso em $09 / 04 / 2020$

por G1SC e NCSTV - 06/04/2020. Denúncias de violência doméstica aumentam em Blumenau durante quarentena. Disponível em: <https://g1.globo.com /sc/santa-catarina /noticia/2020/04/06/denuncias-de-violencia-domestica-aumentam-em-blumenau-durantequarentena.ghtml>. Acesso em: 12 abr. 2020.

GRUPO LIBERAL. da redação 03/04/2020. Delegacia Eletrônica já registra Violência Doméstica. Disponível em: <https://liberal.com.br/brasil-e-mundo/brasil/delegacia-eletroni ca-comeca-a-registrar-violencia-domestica-1176488/>. Acesso em: 12 abr. 2020.

IPEA. Instituto de Pesquisa Econômica Aplicada. Atlas da Violência 2018. Disponível em: $<$ http://www.ipea.gov.br/portal/index.php?option=com_contente\& view=article \&id=33410 \&itemid=432>. Acesso em: 11 mar. 2019.

ISTOÉ. Edição no 2622 10/04. Publicada em 03/04/20. Quarentena Eleva Risco de Violência Doméstica. Disponível em: <https://istoe.com.br/quarentena-eleva-risco-deviolencia-domestica/>. Acesso em: 12 abr. 2020.

MEDIUM. Autora: Gabriela Moura. Violência contra a mulher aumenta com pandemia de Covid-19 - Quarentena deixa mulheres mais vulneráveis a seus agressores. Disponível em: $<$ https://medium.com/@metaforica_gabi/violence-against-women-grows-alongside-covid-19pandemic-1cef2281f24d>. Acesso em: 12 abr. 2020.

OAB-BA. Comissão de Proteção aos Direitos da Mulher da OAB-Ba. Necessidade de implantação da delegacia Digital no combate à Violência Doméstica durante o isolamento e distanciamento social. Disponível em: <https://www.instagram.com/p/BrdufNlZE2/>. Acesso em: 12 abr. 2020.

OEA. Organização dos Estados Americanos. processo de no 12.051/OEA, relatório nº 54/01. Disponível em: <http://www.sbdp.org.br/arquivos/material/299_Relat\%20n.pdf. >. Acesso em: 12 abr. 2020.

PORTAL R7. Reportagem de Nayara Fernandes de 01/04/2020. Sem lugar seguro: quarentena expõe crise de Violência doméstica no País. Disponível em: <https://noticias. r7.com/saude/coronavirus/sem-lugar-seguro-quarentena-expoe-crise-de-violen cia-domesticano-pais-01042020>. Acesso em: 09 abr. 2020.

SÃO PAULO. do Portal do Governo 03/04/2020. SP anuncia que Delegacia Eletrônica fará atendimento virtual de violência doméstica. Vítimas desse tipo de crime têm prioridade no atendimento virtual e serviço presencial nas DDMs continua funcionando normalmente. Disponível em: <https://www.saopaulo.sp.gov.br/noticias-coronavirus/ governo-de-sp-anun cia -novas-medidas-para-intensificar-combate-ao-coronavirus/>. Acesso em: 12 abr. 2020.

Revista de Gênero, Sexualidade e Direito | e-ISSN: 2525-9849 | Encontro Virtual | v. 6 | n. 2 | p. $66-83$ | Jul/Dez. 2020. 
WAISELFISZ, Júlio Jacobo. MAPA DA VIOLÊNCIA 2015 - Homicídio de Mulheres no Brasil. 1 ed. Flacso, Brasília - Distrito Federal, 2015. 79 p. Disponível em: <https://www. mapadaviolencia.org.br/pdf2015/MapaViolencia_2015_mulheres.pdf $>$. Acesso em: 02 abr. 2020.

XAVIER, Elton Dias; TEIXEIRA, Ana Paula Fernandes. Justiça restaurativa e a tendência expansionista no direito penal: nova forma de pensar o paradigma punitivo. - 357-375 pp In: VALOIS, Luiz Carlos; SANTANA, Selma; MATOS, Taysa; ESPIÑEIRA, Bruno. [Orgs.] JUSTIÇA RESTAURATIVA. Belo Horizonte: D’Plácido, 2017, 497 p.

TIINSIDE. Por Alex Felipelli, 09/09/13. O mundo hiperconectado: uma nova era de oportunidades. Disponível em:<https://tiinside.com.br/09/09/2013/mundo-hiperconectadoera-oportunidades/.> Acesso em: 12 abr. 2020.

TUASAÚDE. Autora: FARIA, Claudia; (Psicóloga). Transtornos Mentais mais comuns:

Como identificar e tratar. Disponível em: 〈https://www.tuasaude.com/transtor nos-mentais/.>. Acesso em: 09 abr. 2020. 